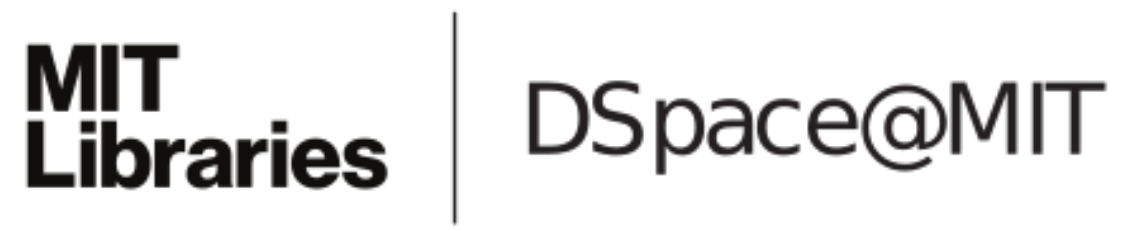

\author{
MIT Open Access Articles
}

Price Stickiness: Empirical Evidence of the Menu Cost Channel

The MIT Faculty has made this article openly available. Please share how this access benefits you. Your story matters.

Citation: Anderson, Eric, Nir Jaimovich, and Duncan Simester. "Price Stickiness: Empirical Evidence of the Menu Cost Channel." Review of Economics and Statistics 97, no. 4 lOctober 2015): 813-26. (C 2015 The President and Fellows of Harvard College and the Massachusetts Institute of Technology

As Published: http://dx.doi.org/10.1162/REST_a_00507

Publisher: MIT Press

Persistent URL: http://hdl.handle.net/1721.1/100494

Version: Final published version: final published article, as it appeared in a journal, conference proceedings, or other formally published context

Terms of Use: Article is made available in accordance with the publisher's policy and may be subject to US copyright law. Please refer to the publisher's site for terms of use. 


\title{
PRICE STICKINESS: EMPIRICAL EVIDENCE OF THE MENU COST CHANNEL
}

\author{
Eric Anderson, Nir Jaimovich, and Duncan Simester*
}

\begin{abstract}
A leading explanation in the economic literature is that monetary policy has real effects on the economy because firms incur a cost when changing prices. Using a unique database of cost and retail price changes, we find that variation in menu costs results in up to $13.3 \%$ fewer price increases. We confirm that these effects are allocative and have a persistent impact on both prices and unit sales. We provide evidence that the menu cost channel operates only when cost increases are small in magnitude, which is consistent with theory and provides the first empirical evidence of boundary conditions.
\end{abstract}

\section{Introduction}

$\mathrm{W}$ HY does monetary policy have real effects on the economy? A leading explanation in the macroeconomics literature is that firms incur a cost (a "menu cost") when changing their prices, which results in less frequent price adjustments. This framework of "state-dependent" pricing has been studied extensively since the work of Barro (1972) and Sheshinski and Weiss (1977). ${ }^{1}$

Unfortunately, there is almost no empirical evidence that validates and quantifies the effects of menu costs on price stickiness (in what follows we refer to this as the "menu cost channel"). The reason is that such an analysis requires a unique data set that is hard to obtain. Specifically, the appropriate data set has at least two prerequisites. First, it needs to include measures (or proxies) of menu costs that vary across products, time, or geography. Second, it needs to include accurate measures of cost shocks and other covariates. These are required to rule out the possibility that an interaction between the magnitudes of the menu costs and other factors contributes to the decision to change prices.

We report the findings from a large-scale empirical study with a national U.S. retailer that enables us to construct such a data set. A key to our identification of the menu cost channel relies on a pricing rule that the retailer enforces. Like many other retailers, the firm links the prices of different color and flavor variants of a product. If the price of one variant changes, then the prices of all other variants need to

Received for publication October 24, 2012. Revision accepted for publication July 24, 2014. Editor: Mark W. Watson.

* Anderson: Northwestern University; Jaimovich: Duke University and NBER; Simester: MIT.

This paper has benefited from comments by Jeff Campbell, Alberto Cavallo, Nathan Fong, Robert Hall, Pete Klenow, Roy Mill, Emi Nakamura, Nicolas Vincent, Ivan Werning, and participants at the 2011 NBER Pricing Dynamics workshop, 2011 Milton Friedman Institute Pricing Dynamics Conference, the 2011 Yale Customer Insights Conference, and seminar participants at the University of Alberta and the University of Wisconsin.

A supplemental appendix is available online at http://www.mitpress journals.org/doi/suppl/10.1162/REST_a_00507.

${ }^{1}$ While important details differ across the work that followed, a central and common assumption is that a fixed cost must be incurred on a price change. See, for example, other prominent examples that built on this work: Akerlof and Yellen (1985a, 1985b), Mankiw (1985), Caplin and Spulber (1987), Caplin and Leahy (1991, 1997), Bertola and Caballero (1990), Danziger (1999), Dotsey, King, and Wolman (1999), Burstein (2006), Golosov and Lucas (2007), and Gertler and Leahy (2008). change as well. As we later show, there is significant variation in the number of links across products.

The menu costs we study are attributed to in-store labor costs. Consider the task of changing the price of Cheerios (which has one variant) with changing the price of nail polish (for which one item has 62 different color variants). To change the price, a store employee must locate the product in the store. Once the employee locates the Cheerios, he or she simply changes a single on-shelf price sticker. However, when changing the price of nail polish, the employee must match each sticker with the shelf location of each of the 62 colors. The retailer conducts time and motion studies that clearly show that the time to change the price of an item increases with the number of variants. ${ }^{2}$

For this retailer, like most others, in-store labor costs represent the largest expense after cost of goods sold, and therefore these expenses are carefully monitored and budgeted. In the short run, labor capacity is fixed, and so a small number of additional price changes on any single day do not result in the firm's hiring an extra employee or paying overtime. But it does create an opportunity cost as less labor is allocated to valuable activities such as stocking shelves, answering customers' questions, or completing transactions. Returning to our example, changing the price of nail polish requires a larger time allocation than Cheerios, and this imposes a larger opportunity cost by reducing the time available for these other activities. In section II, we provide additional details on the specific policies this retailer adopts to manage these opportunity costs.

The firm's policy of linking prices across variants provides an ideal opportunity to measure whether these costs affect price stickiness. If these types of menu costs play no part in the decision to change prices, then we would expect more price variation on items with more variants, as these items tend to have higher unit sales volumes. However, if menu costs increase with the number of variants and these costs contribute to price stickiness, this will tend to reduce price variation on items with more variants. This identification strategy, together with our access to clean measures of cost shocks and a rich set of covariates for each product, allows us to validate the menu cost channel. ${ }^{3}$

\footnotetext{
${ }^{2}$ Midrigan (2012) assumes in his theoretical work that there exists a fixed cost of changing a single price but that the cost of changing additional prices is 0 . This could lead to outcomes in which items with more variants have a lower menu cost, which leads to a higher likelihood of price changes in response to cost shocks. We address his work later in this section.

${ }^{3}$ These cost change events are difficult to infer from other data sources, such as the widely used Dominick's data. For example, Dominick's data do not report the regular price of an item, and the cost metric may capture a weighted average cost of inventory (Peltzman, 2000). These limitations make it difficult to identify the timing or magnitude of cost or regular price changes.
} 
We find that among products that have a single variant, a cost increase leads to an immediate price increase $71.2 \%$ of the time. But if a product has seven or more variants, then the probability of a price increase is just $59.8 \%$. We calculate that up to $13.3 \%$ more price increases would have been observed if all items had only a single variant.

Importantly, we show that these effects are persistent. Price increases that do not occur at the time of a cost shock are not merely delayed. Among items for which prices are not initially increased, only $5.8 \%$ have a price increase within the next 90 days. When we look over longer horizons (e.g., 360 days), there is no evidence of a delayed price increase. Finally, we confirm that the effects we measure have long-run impacts on both prices and unit sales.

We also identify boundary conditions on the menu cost channel. First, we find no evidence of a menu cost channel when investigating whether the firm decreases price in response to a cost decrease. This is consistent with past evidence of asymmetries between price increases and price decreases. ${ }^{4}$ Among the cost increases, we anticipate that menu costs will be weighed against the cost of not increasing a price. For this reason, when the cost increase is large, we do not expect that the menu cost channel will affect pricing decisions. This is what we observe in our data. When cost increases are large, the probability of a price increase is also large. It is also invariant to the number of product linkages, indicating that menu costs do not play an important role. It is only when the cost increase is small that we observe the menu cost channel influencing pricing decisions.

The contribution of this paper is to provide clear empirical evidence of the menu cost channel. We identify institutional features that create variation in menu costs across products. We then show that when a retailer is faced with a cost increase, these menu costs have a meaningful impact on the decision to raise the price. Indeed, menu costs play an important role in contributing to price stickiness.

\section{A. Related Literature}

There have been surprisingly few attempts to directly measure the link between menu costs and the frequency of price changes. A search of the literature reveals one important predecessor. Levy et al. (1997) begin by decomposing the cost of changing prices in a sample of U.S. supermarkets and then examining how item pricing laws (which require separate pricing stickers on each unit) affect the frequency of price changes. It is this second portion of their paper that is most closely related to this paper. The four retailers in their study that are not subject to item pricing laws change prices on $15.6 \%$ of products each week. In

\footnotetext{
${ }^{4}$ We discuss this literature in sections III and V. This result may also partly reflect a lack of statistical power (cost decreases are less common).
}

contrast, a different retailer, which is subject to item pricing laws, changes prices on just $6.3 \%$ of products weekly. ${ }^{5}$ They also show that for the retailer subject to item pricing laws, price changes occur three times more frequently on the items exempt from item pricing than on items for which item pricing is required. This is perhaps the first study to directly measure a link between menu costs and price stickiness. The key differences with respect to our work is that their data are at an aggregate level using either storelevel data or aggregating across large groups of products (those subject to item pricing and those that are exempt). ${ }^{6}$ As a result, they do not have access to detailed controls describing differences across stores and products. In particular, they do not have access to cost data. Controlling for cost shocks is crucial; without it, we cannot refute the hypothesis that the probability of price adjustment differs across products merely because of different cost shocks (or other product differences).

The same research team also has a series of studies in which they document the magnitude of menu costs in different markets. For example, Levy et al. (1998) and Dutta et al. (1999) document the price change process and provide direct measurements of menu costs at large U.S. supermarket retailers and drugstores (respectively). The menu costs that they document are primarily of in-store labor costs. ${ }^{7}$ While these studies provide valuable documentation of the importance of in-store labor costs when adjusting retail prices, neither of the studies measures how these costs influence the frequency of price changes, the primary focus of this paper.

Other empirical research investigating menu costs has relied on indirect inferences of menu costs through the frequency and magnitude of price adjustments. ${ }^{8}$ This includes a recent stream of papers that argues that there are economies of scope from changing prices. A notable example is Midrigan (2011). Citing evidence in Lach and Tsiddon (2007) and Levy et al. (1997), he assumes in his theoretical work that there exists a fixed cost of changing a single price but that the cost of changing additional prices is 0 . Alvarez and Lippi (2014) make a similar assumption in an analytical model of multiproduct firms. On the empirical side, Bhattarai and Schoenle (2014) use the PPI data set and show that

\footnotetext{
${ }^{5}$ In a follow-up to Levy et al., Owen and Trzepacz (2002) report weaker findings when controlling for retailer differences by using retailers that operate in both regions that require item pricing and regions that do not.

${ }^{6}$ The unit of analysis in this study is a cost change on an individual product.

${ }_{7}^{7 n}$ contrast, Zbaracki et al. (2004) measure the magnitude of the costs of price adjustments in industrial markets and highlight the importance of managerial costs (information gathering, decision making, and communication) and customer costs (communication and negotiation).

${ }^{8}$ Examples include Rotemberg (1982), Cecchetti (1986), Carlton (1986), Danziger (1987), Ball, Mankiw, and Romer (1988), Lach and Tsiddon (1992, 1996), Ball and Mankiw (1992), Kashyap (1995), Warner and Barsky (1995), Golosov and Lucas (2007), Midrigan (2007), Bils and Klenow (2004), Nakamura and Steinsson (2008), and Klenow and Kryvtsov (2008).
} 
wholesalers that sell more goods change prices more frequently. They interpret this as evidence of economies of scope in the cost of changing prices. As Bhattarai and Schoenle (2014) emphasize, they focus on "price-setting at the production, not the distribution side." This is an important distinction, because the key institutional feature in our paper is the in-store labor cost, a retail industry characteristic (we discuss this in detail in section II). Because of these in-store labor costs, the retailer closely monitors the frequency of price changes. This contributes to our finding that products with more variants are less likely to have price increases after a cost increase, which is consistent with a cost function that increases with the number of variants. More generally, we believe that in the real world, both types could exist: the one we identify as well as the economies of scope Bhattarai and Schoenle (2014) refer to. Our findings suggest that the cost function increasing with the number of variants dominates in our data set rather than any "economies of scope in the menu cost technology."

The paper proceeds as follows. In section II, we describe our data together with the institutional processes that the retailer that provided the data uses. In section III, we estimate the menu cost channel. Specifically, we investigate whether the additional opportunity cost of changing prices on items with more variants is of sufficient magnitude to influence the firm's pricing decisions. The finding that the firm is less likely to raise prices on items that have more variants provides empirical evidence that menu costs contribute to pricing decisions. In section IV, we investigate whether the effect is temporary or enduring by investigating how quickly the firm changes prices in future periods. We also ask whether the effects are allocative by evaluating how they affect quantities sold in subsequent periods. In section $\mathrm{V}$, we investigate the response to cost decreases. The paper concludes in section VI with a review of the findings.

\section{Description of the Data and Institutional Background}

The analysis in this paper uses data provided by a national retailer that operates a large number of stores that sell items in grocery, health and beauty, and general merchandise product categories. We begin by describing this retailer's policy of linking prices across items. We then review details of the firm's institutional processes that illustrate the importance of in-store labor costs. We conclude the section by describing the three data sets that we use in our analysis.

\section{A. Uniform Pricing Rules (Linkages)}

Like many other retailers the firm follows a uniform pricing rule, which requires that all variants of a product have the same price. For example, a product such as Stacy's Pita Chips has 2 variants (cinnamon and parmesan), and Gold Em Spices have 25 variants. This retailer assigns a common primary stockkeeping unit (PrimarySKU) to a family of variants, and then a stockkeeping unit (SKU) number to every individual variant. A key feature of the data is that the retail price is the same for every SKU under the same PrimarySKU. ${ }^{9}$ Thus, if the retailer decides to change the price of the product, prices for all of its variants must change.

The use of uniform pricing policies is common across grocery retailers, and this has led to a growing academic literature focused on explaining why retailers adopt this practice. Explanations for uniform pricing have focused on simplifying the purchasing decision (Hauser \& Wernerfelt, 1990; Iyengar \& Lepper, 2000; Draganska \& Jain, 2001), avoiding an adverse quality signal for the lower-priced item (Anderson \& Simester, 2001; Orbach \& Einav, 2007), the managerial cost of setting different prices for different variants (Leslie, 2004; McMillan, 2005), homogeneity in consumer preferences across different flavors (Draganska \& Jain, 2006; Anderson \& Dana, 2009), demand uncertainty (Orbach \& Einav, 2007), and customer fairness (Andersen $\&$ Simester 2008). ${ }^{10}$

\section{B. In-Store Labor Costs}

In-store labor costs represent a large portion of this retailer's cost structure. The retailer establishes budgets for labor expenses at each store, and complying with these budgets plays an important role in determining both bonuses and promotions. As part of the monitoring of labor expenses, the number of regular price changes allowed is 100 SKUs per day, five days per week (Tuesday through Saturday). As a basis for comparison, this retailer's stores typically stock approximately 20,000 SKUs.

The number of price changes is calculated at the variant level, so that changing the price of two different colors of the same item is counted as two price changes. The policy is enforced by a reporting system that counts how many days each month there are more than 100 daily price changes. The same report also tracks how many items receive more than one price change within a 32-day period and how many price changes are smaller than 4 cents. Part of the annual bonuses of specific employees depends on these measures; they receive smaller bonuses when there are too many daily price changes, prices of individual items are changed too frequently, or there are too many small price changes. In the online appendix, we report the average daily compliance for these three pricing rules for 2004 through 2008. While compliance with the 4 cent policy is very high (averaging over 99\%), there are many instances

\footnotetext{
${ }^{9}$ The prices are identical, not just perfectly correlated. This is true not just for regular prices but also for sale prices.

${ }^{10}$ It is important to clarify that the paper does not address why this retailer has adopted uniform pricing. More generally, the optimality of the firm's pricing decisions is beyond the scope of the paper. We are also unable to speculate on how the firm's policies would change if there were a dramatic increase in the inflation rate.
} 
in which the retailer does not comply with the other two policies. In particular, compliance with the daily limit on price changes averages $91.8 \%$, indicating that the restriction on the frequency of price changes is not trivially satisfied. As we discussed in section I, if the number of price changes exceeds this capacity, labor is reallocated within the store. The reallocated labor is substituted from activities such as inventory management, restocking and merchandising shelves, and serving or assisting customers.

The decision to measure the frequency of price changes at the variant level is informative. Price changes on items that have multiple variants are interpreted as multiple price changes. Thus, the uniform pricing rule that the retailer follows implies that changing the price of an item with more variants more quickly exhausts the planned capacity.

It is the uniform pricing rule that gives rise to our identification of the menu cost channel. If the cost of changing prices increases with the number of variants, then this rule induces a natural variation in the cost of changing prices across items. Holding everything else constant, products with more variants invoke a larger cost.

\section{Description of the Data}

We obtained three data sets from the retailer:

1. A record of every wholesale cost and regular retail price change over a 55-month period

2. A product hierarchy mapping individual SKUs to PrimarySKUs

3. Two hundred weeks of transaction data for each item sold at a sample of 102 stores

The first data set describes every wholesale cost change and every change to the regular retail price during the period between March 2005 and September 2009. These data are compiled into monthly reports that senior management uses to monitor variation in profit margins in each product category, together with the frequency of price and cost changes. The firm interprets the cost data as the effective marginal cost of an item when conducting analysis to support managerial decisions. Whenever the wholesale price changes, this will immediately get reflected in our data set, unlike data sets in which the wholesale price is an "average acquisition cost." With few exceptions, the cost changes are permanent, not transitory (cost changes typically occur once every 12 to 24 months). ${ }^{11}$ The wholesale costs are generally identical for different variants of the same PrimarySKU, and the cost changes on the variants are essentially perfectly correlated. The price and cost change

\footnotetext{
${ }^{11}$ In are a small number of instances, there are multiple cost changes in the same month. We randomly select just one of these observations for use in the analysis. This leads to the omission of 126 cost increases and 56 cost decreases. We also investigated retaining these observations or aggregating multiple cost changes within a month into a single observation. These approaches had essentially no impact on the findings.
}

reports also include the total unit volume for the item over the prior twelve months. In the online appendix, we provide formal definitions and summary statistics for each of these variables.

The price and cost change database focuses solely on regular price changes and does not consider price changes due to temporary sales. Therefore, like Golosov and Lucas (2007) and Nakamura and Steinsson (2008), we exclude temporary sales from our analysis. ${ }^{12}$ For ease of exposition, we use the term prices to denote regular retail prices.

An important feature of the data is that when the wholesale cost changes, the firm makes an explicit decision about whether to change the retail price at the same time. In particular, when the wholesale cost changes, the record of the cost change indicates whether the retail price was changed at the same time. Discussions with the company confirm that when the category manager communicates the cost change to the operations team, the category manager is required to provide a decision on whether to change the retail price. We exploit the simultaneity of these cost and retail price events in the next section by investigating whether a cost increase was less likely to lead to a coinciding price increase for items that have a large number of variants. In section IV, we extend the time horizon by investigating whether cost increases lead to price increases in subsequent (or prior) periods.

Our second source of data is a hierarchy mapping individual SKUs to PrimarySKUs. We use these data to calculate the number of variants for each PrimarySKU. Throughout the paper (unless noted), we use a product hierarchy dated July 2010. The intersection of the cost data and the product hierarchy yields 11,368 cost increases and 4,194 cost decreases.

The third data set describes weekly transactions at a sample of 102 of the firm's stores. This transaction data extend from the first week in 2006 through October 2009 (200 weeks). We will use these data in section IV to investigate whether the firm's initial decision to increase prices has an enduring impact on prices and quantities sold.

A shortcoming of our paper is that the results rely on a single (albeit very large) retailer. This introduces a risk that findings using data from this firm are not representative of other firms. In response, we begin by noting that while uniform pricing is a common practice among retailers, the generalizability of our findings does not rely on other retailers enforcing the same policy. We merely use the policy at this retailer to identify the variation in menu costs across items.

\footnotetext{
${ }^{12}$ At this retailer, temporary sales are implemented through a different operational process and have separate labor budgets allocated to them. They are not counted in the 100 per day price change capacity and in almost all cases are funded by manufacturers through a separate funding channel that does not affect the wholesale costs that we observe. In separate research, we discuss these institutional differences in detail and report evidence that in response to a wholesale cost increase, the entire increase in retail prices comes through regular price increases (Anderson et al. 2015).
} 


\begin{tabular}{ccc}
\multicolumn{2}{c}{ Table 1.-Frequency of Cost and Price Changes } \\
\hline \hline & Cost Increases & Cost Decreases \\
\hline Price increased & $70.6 \%$ & $5.7 \%$ \\
Price decreased & $0.9 \%$ & $9.2 \%$ \\
No price change & $28.5 \%$ & $85.2 \%$ \\
Sample size & 11,368 & 4,194 \\
\hline The table reports the percentage of times that the retail price changed when the cost changed.
\end{tabular}

Instead what we require is that other retailers place the same focus on managing in-store labor costs.

The existence and magnitude of in-store labor costs as a source of menu costs is now well documented in the literature (see the discussion of related literature in section I). Moreover, this retailer's focus on managing in-store labor costs is standard industry practice. Because a small reduction in labor costs can have a large impact on net profit margin, retailers carefully monitor labor costs, and labor capacity is carefully planned for all standard operational tasks. ${ }^{13}$ Time and motion studies are commonly used to identify opportunities to reduce the time spent on standard in-store activities. For example, an apparel retailer found that saving 1 second from the checkout process for each customer would produce savings of $\$ 15,000$ in annual labor costs across its 34 stores (O'Connell, 2008). Similarly, another retailer reported that flipping a box of bananas over prior to stocking could enable employees to grasp more bananas at a time and speed up the stocking process, yielding annual savings of $\$ 100,000$.

\section{Measuring Menu Costs Using the Number of Variants}

In this section we investigate how the number of variants influences the retailer's decision to increase prices at the time of a cost increase. We begin by describing the frequency and magnitude of cost and price changes in our data set. We then consider the distribution of price and cost changes by their absolute value. The motivation for this stems from the common prediction in menu cost models that if the cost of changing prices is meaningful, we should not observe many small price changes, particularly for higher-valued items. Indeed we show that our data are characterized by almost no small price changes. We then move to the main part of the section and describe the number of variants in our sample of PrimarySKUs. We conclude the section by evaluating how the probability of a price change depends on the number of variants.

Recall that our data include 11,368 observations in which the cost increased and 4,194 observations in which it

\footnotetext{
${ }^{13}$ Labor costs are typically the second largest source of retailers' costs and are directly controllable by the retailer (Atlanta Retail Consulting, 2011). For a typical grocery store, the Food Marketing Institute (2008) estimates that labor costs are $14.8 \%$ of total sales and that net profit margins are only $3 \%$ of total sales.
}

Table 2.-Absolute Size of Cost and Price Changes by Prior Retail Price

\begin{tabular}{lcccr}
\hline \hline $\begin{array}{l}\text { Prior } \\
\text { Retail Price }\end{array}$ & $\begin{array}{c}10 \text { Cents } \\
\text { or Less }\end{array}$ & $\begin{array}{c}20 \text { Cents } \\
\text { or Less }\end{array}$ & $\begin{array}{c}50 \text { Cents } \\
\text { or Less }\end{array}$ & $\begin{array}{l}\text { Sample } \\
\text { Size }\end{array}$ \\
\hline $\begin{array}{l}\text { Absolute size of price changes } \\
\text { Under } \$ 5\end{array}$ & $16 \%$ & $44 \%$ & $89 \%$ & 5,326 \\
$\$ 5$ to $\$ 10$ & $3 \%$ & $13 \%$ & $67 \%$ & 3,834 \\
$\$ 10$ to $\$ 15$ & $3 \%$ & $4 \%$ & $33 \%$ & 1,654 \\
$\$ 15$ to $\$ 20$ & $1 \%$ & $3 \%$ & $20 \%$ & 812 \\
$\$ 20$ to $\$ 30$ & $1 \%$ & $2 \%$ & $10 \%$ & 647 \\
$\$ 30$ to $\$ 40$ & $4 \%$ & $5 \%$ & $13 \%$ & 215 \\
$\$ 40$ to $\$ 50$ & $0 \%$ & $0 \%$ & $8 \%$ & 124 \\
Over $\$ 50$ & $0 \%$ & $0 \%$ & $4 \%$ & 212 \\
Total & $8 \%$ & $23 \%$ & $63 \%$ & 12,824 \\
Absolute size of cost changes & & & \\
Under $\$ 5$ & $62 \%$ & $85 \%$ & $97 \%$ & 7,018 \\
$\$ 5$ to $\$ 10$ & $24 \%$ & $50 \%$ & $85 \%$ & 4,363 \\
$\$ 10$ to $\$ 15$ & $8 \%$ & $15 \%$ & $51 \%$ & 1,746 \\
$\$ 15$ to $\$ 20$ & $5 \%$ & $8 \%$ & $36 \%$ & 888 \\
$\$ 20$ to $\$ 30$ & $4 \%$ & $7 \%$ & $20 \%$ & 764 \\
$\$ 30$ to $\$ 40$ & $2 \%$ & $4 \%$ & $16 \%$ & 329 \\
$\$ 40$ to $\$ 50$ & $4 \%$ & $5 \%$ & $13 \%$ & 217 \\
Over $\$ 50$ & $5 \%$ & $6 \%$ & $8 \%$ & 237 \\
Total & $36 \%$ & $55 \%$ & $77 \%$ & 15,562 \\
\hline
\end{tabular}

decreased (where the unit of analysis is a PrimarySKU). In table 1, we report how often these cost changes resulted in price changes (at the time of the cost change).

While cost increases often resulted in a price increase, cost decreases rarely led to price decreases. The potential for asymmetries in the frequency of price increases versus price decreases has been discussed elsewhere in the literature (Peltzman, 2000). ${ }^{14}$ They were also acknowledged by the retailer's management, who confirmed that the firm uses different criteria when deciding whether to change prices in response to a cost increase versus a cost decrease. For this reason we initially restrict attention to cost increases, which represent almost $75 \%$ of the data. In section $\mathrm{V}$, we turn attention to cost decreases and highlight additional asymmetries in the retailer's response.

\section{A. Size of the Cost and Retail Price Changes}

The size of the retail price changes offers a preliminary check on the role of menu costs at this retailer. If menu costs are meaningful, then we should not observe many small price changes, particularly for higher-valued items. In table 2 we report the distribution of the absolute magnitude of the retail price changes grouped by the prior retail price of the item. As a basis for comparison, we also report the distribution of the absolute size of the cost changes.

\footnotetext{
${ }^{14}$ Other references include Karrenbrock (1991), Neumark and Sharpe (1992), Borenstein, Cameron, and Gilbert (1997), Jackson (1997), Noel (2009), Hofstetter and Tover (2010), and Green, Li, and Schurhoff (2010). Peltzman (2000) does not find any evidence of this asymmetry when studying price changes at Dominick's Finer Foods in Chicago. He attributes this null finding to a distinction between individual firm decisions and market outcomes. Our findings could be considered a counter example to Peltzman's supermarket example. Notably, the retailer in this study and the supermarket in Peltzman's study compete in similar retail markets.
} 
Table 3.-Frequency Distribution of Number of SKUs under EACH PRIMARYSKU

\begin{tabular}{ccccc}
\hline \hline $\begin{array}{l}\text { Number } \\
\text { of SKUs }\end{array}$ & $\begin{array}{c}\text { PrimarySKU } \\
\text { Frequency }\end{array}$ & $\begin{array}{c}\text { SKU } \\
\text { Frequency }\end{array}$ & $\begin{array}{c}\text { Revenue } \\
\text { Weighted }\end{array}$ & $\begin{array}{c}\text { Units } \\
\text { Weighted }\end{array}$ \\
\hline 1 & $79.9 \%$ & $49.9 \%$ & $59.1 \%$ & $50.2 \%$ \\
2 & $9.3 \%$ & $11.6 \%$ & $13.5 \%$ & $14.0 \%$ \\
3 & $4.2 \%$ & $7.8 \%$ & $8.2 \%$ & $8.6 \%$ \\
4 & $2.3 \%$ & $5.7 \%$ & $5.3 \%$ & $6.6 \%$ \\
5 & $1.2 \%$ & $3.9 \%$ & $3.5 \%$ & $4.1 \%$ \\
6 & $0.9 \%$ & $3.3 \%$ & $2.6 \%$ & $3.7 \%$ \\
7 & $0.5 \%$ & $2.2 \%$ & $1.6 \%$ & $1.8 \%$ \\
8 & $0.4 \%$ & $1.8 \%$ & $0.8 \%$ & $1.5 \%$ \\
9 & $0.3 \%$ & $1.5 \%$ & $0.6 \%$ & $0.7 \%$ \\
10 & $0.1 \%$ & $0.9 \%$ & $0.3 \%$ & $0.9 \%$ \\
11 & $0.1 \%$ & $0.6 \%$ & $0.3 \%$ & $1.0 \%$ \\
12 & $0.1 \%$ & $0.9 \%$ & $0.4 \%$ & $0.6 \%$ \\
13 & $0.1 \%$ & $1.2 \%$ & $0.7 \%$ & $1.4 \%$ \\
14 & $0.1 \%$ & $0.9 \%$ & $0.3 \%$ & $0.6 \%$ \\
15 & $0.1 \%$ & $0.9 \%$ & $0.3 \%$ & $0.7 \%$ \\
Over 15 & $0.4 \%$ & $7.0 \%$ & $2.6 \%$ & $3.6 \%$ \\
\hline
\end{tabular}

The table reports a frequency distribution of the NUMBER OF SKUS by PrimarySKU, SKU, revenue, and units. The revenue and units measures are calculated using the prior 12 months of sales data (reported in the cost and price change reports). The sample includes 8,072 PrimarySKUs for which there was either a cost change or retail price change in our 55-month data period. In all four distributions, we exclude items for which NUMBER OF SKUS or either of the weighting variables is missing.

Small cost changes are common in the data, but small price changes are rare. For example, $35 \%$ of the 15,562 cost changes are less than 10 cents in absolute magnitude, but just $4 \%$ of the 12,824 price changes fall within this range. This scarcity of small price changes is what we would expect in the presence of menu costs.

\section{B. Number of Variants}

In table 3 we report frequency distributions of the number of SKUs under each PrimarySKU (NUMBER OF $S K U S)$. The first column is a distribution of the number of PrimarySKUs, and the second column is a distribution of the number of SKUs. The last two columns report the distribution of revenue and units sold in the previous twelve months. The 8,072 PrimarySKUs contain of 12,931 individual SKUs with an average of 1.60 SKUs per PrimarySKUs and a maximum of 62 (the brand of nail polish referred to in the opening paragraphs). The frequency distribution reveals that while PrimarySKUs with a single variant represent $79.9 \%$ of all PrimarySKUs, they represent only $59.1 \%$ of revenue and $49.9 \%$ of individual SKUs.

\section{Number of Variants and the Probability of a Price Change}

In figure 1 we report how the probability of a price increase (following a cost increase) changes according to the NUMBER OF SKUS. We report both weighted and unweighted averages, where the weighting uses the previous twelve months of revenue for each PrimarySKU. The findings reveal a strong negative relationship: items with more SKUs were less likely to receive a price increase fol-
Figure 1.-Probability Prices Increase Following a Cost InCREase
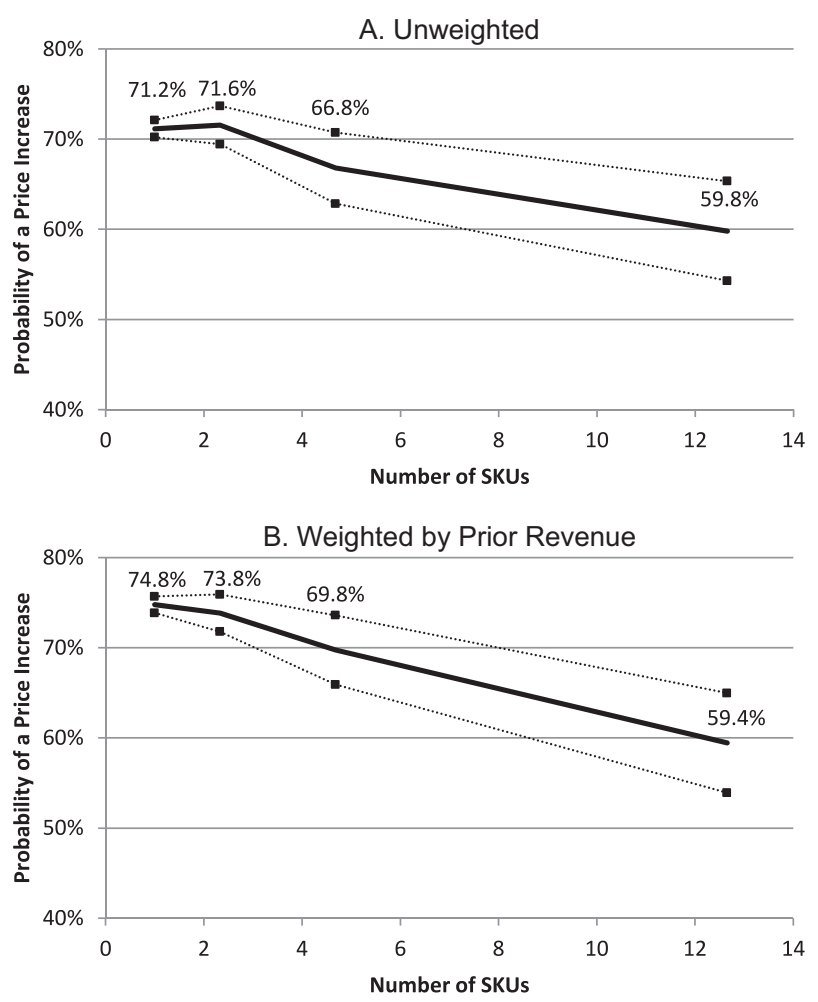

The panels report the probability of a price increase following a cost increase. The square markers indicate the $95 \%$ confidence interval. We report both weighted and unweighted averages, where the weighting uses total revenue over the prior twelve months. A small number of observations are missing for this weighting variable. To maintain a consistent comparison, we omit these observations from both the weighted and unweighted averages.

lowing a cost increase. This is a key finding in the paper and is consistent with the firm's forgoing price increases in order to avoid larger menu costs on items with additional variants.

To evaluate the importance of the effects in figure 1, it is helpful to understand how the reluctance to raise prices on items with more variants affects the overall frequency of price changes at this firm. We address this issue by asking the following question: If the probability of a price increase was the same for items with multiple variants as it is for items with a single variant, how many more price increases would we see? To answer this question, we calculate the probability of a price increase following a cost increase for items that had only a single variant. We restrict attention to items that had at least one cost increase in our 55-month data period.

There were 8,697 cost increases on items with a single variant, and these increases resulted in 6,188 price increases. Therefore, the probability of a price increase following a cost increase on an item with a single variant is $71.2 \%$ (see figure 1A). Using this probability we calculate how many projected price increases we would expect to observe on items with multiple variants if price increases on these items occurred at the same rate. The findings are 
Table 4.-Overall Frequency of Price Increases on Items WITH Multiple Variants

\begin{tabular}{lcc}
\hline \hline & Unweighted & $\begin{array}{c}\text { Weighted } \\
\text { (by Revenue) }\end{array}$ \\
\hline Cost increases & 10,491 & 10,491 \\
Actual price increases & 6,924 & 6,924 \\
Projected price increases & 7,464 & 7,845 \\
Projected minus actual & 540 & 921 \\
\hline The table reports the actual number of cost and price increases on items with at least two variants. The \\
table also projects how many price increases would occur if price increases on these items occurred at \\
the same rate as they occur on items with a single variant. We report both weighted and unweighted \\
results, where the weighting uses total revenue over the prior twelve months.
\end{tabular}

reported in table $4 .{ }^{15}$ Cost increases on items with multiple variants represented 10,491 increases on individual SKUs. If price increases occurred at the same rate as on items with a single variant, then we would have observed 7,465 price increases, $540(7.8 \%)$ more than we actually observed. When weighting by revenue, there would have been 921 additional price increases, or $13.3 \%$ more.

These initial findings are consistent with our interpretation that the menu costs associated with changing the retail price are larger when an item has more variants and that this leads to price stickiness. However, this is not the only explanation for these univariate results. Notably, it is possible that the relationship may reflect an interaction between NUMBER OF SKUS and other factors that contribute to the decision to increase prices. Next, we estimate a series of models that control for this possibility.

\section{Other Factors That Contribute to the Decision to Raise the Price}

Several factors in addition to menu costs could contribute to the decision to raise the retail price following a cost increase. For example, we would expect the size of the cost change, the purchase volume, and the prior profit margin to influence the decision to change prices. The larger the cost change, the more likely we will observe a price increase. Larger purchase volumes increase the profit implications of changing prices, and so we would expect retailers to prioritize price increases on higher-volume items. Similarly, discussions with the retailers' pricing managers confirm that they focus on maintaining profit margins within a targeted range. This suggests that if prior to the cost increase the profit margin was low, then the retailer is more likely to respond to cost increases that push the profit margin further outside the targeted range. Collectively these arguments suggest that price increases will be more likely when the cost change and unit volume are larger and the prior profit margin was lower.

An extensive literature has established kink in the demand curve around 99-digit price endings (for example \$2.99). Levy et al. (2011) present evidence that retailers seek to preserve these price endings and are less likely to

\footnotetext{
${ }^{15}$ When weighting by revenue, the probability of a price increase on items with a single variant increases to $74.8 \%$. We use this probability in the weighted analysis.
}

increase prices that currently end with 99 cents (see also Knotek, 2008, 2011). The retailer's pricing policy suggests that this retailer recognizes the kink in the demand function; approximately $48 \%$ of the retailer's prices end with 99 cents. Therefore we construct a binary variable indicating whether the prior retail price ended in 99 cents (Prior 99Cent Price Ending). ${ }^{16}$

It is also possible that a cost increase is more likely to lead to a price increase in larger product categories, in which there are more substitutes. Raising the price in these categories is likely to result in a smaller effect on category sales, as customers are more likely to substitute purchases to other items. To measure product category size, we count the number of PrimarySKUs in each item's product category (Category Size).

In table 5 we report the marginal effects from a logistic model in which the unit of observation is a cost increase on a PrimarySKU, and the dependent variable is a binary variable indicating whether the price increased. The independent variables include the NUMBER OF SKUS for that PrimarySKU. We also report an alternative specification, including the log of NUMBER OF SKUS (model 2). For completeness, the models include fixed year and month effects. The marginal effects for the different specifications are reported in table 5 (to ease exposition, we omit the year and month fixed effects). In all of the models, standard errors are clustered by the month of the observation. ${ }^{17}$

The findings in table 5 confirm that the relationship between NUMBER OF SKUS and the probability of a price increase survives controlling for all of these explanatory variables. The larger the NUMBER OF SKUS, the lower the probability of a price increase following a cost increase.

To help interpret the magnitude of this relationship, we also estimated a linear probability model using OLS. We use binary indicator variables to identify items with two or three variants, four to six variants, or seven or more variants. ${ }^{18}$ These findings are reported as model 3 in table 5 . The findings reveal that if there are two or three variants, the probability of a price increase following a cost increase is 3.3\% lower than when the item has only a single variant. If there are four, five, or six variants, the probability is $10.5 \%$ lower compared to a single variant, and if there are seven or more variants, the probability difference is $17.3 \%$. Figure 2 plots the implied probability of a price increase against the average number of variants in each of the four groups.

Beyond NUMBER OF SKUS, the coefficients for the other variables reveal several additional findings of interest.

\footnotetext{
${ }^{16}$ We also investigated prices that end with 9 cents (such as \$1.49). However, almost all of the prices at this retailer have a 9 cent ending (over 95\%), making it difficult to reliably estimate the impact of a 9 cent ending versus other single-digit endings.

${ }^{17}$ We also considered clustering by the product category. However, there are too many categories for clustering to be meaningful.

${ }^{18}$ This is the grouping of NUMBER OF SKUS that we used in the univariate analysis (see figure 1).
} 
Table 5.-Factors Contributing to the Decision to Raise the Price

\begin{tabular}{|c|c|c|c|}
\hline & Model 1 & Model 2 & Model 3 \\
\hline NUMBER OF SKUS & $\begin{array}{l}-0.01062 * * * \\
(0.0028)\end{array}$ & & \\
\hline Log NUMBER OF SKUS & & $\begin{array}{c}-0.0607 * * * \\
(0.01336)\end{array}$ & \\
\hline NUMBER OF SKUS $=2$ or 3 & & & $\begin{array}{l}-0.0328 * * * \\
(0.0136)\end{array}$ \\
\hline NUMBER OF SKUS $=4$ to 6 & & & $\begin{array}{c}-0.1045^{* * *} \\
(0.0300)\end{array}$ \\
\hline NUMBER OF SKUS $=7$ or more & & & $\begin{array}{l}-0.1732 * * * \\
(0.0406)\end{array}$ \\
\hline Prior 99-cent price ending & $\begin{array}{l}-0.0821 * * * \\
(0.0174)\end{array}$ & $\begin{array}{l}-0.0837 * * * \\
(0.0172)\end{array}$ & $\begin{array}{l}-0.0838 * * * \\
(0.0172)\end{array}$ \\
\hline Size of cost change $(\%)$ & $\begin{array}{l}0.3165^{* * * *} \\
(0.0953)\end{array}$ & $\begin{array}{l}0.3158 * * * \\
(0.0949)\end{array}$ & $\begin{array}{l}0.1950 * * * \\
(0.0573)\end{array}$ \\
\hline Prior profit margin $(\%)$ & $\begin{array}{l}-0.7504 * * * \\
(0.0529)\end{array}$ & $\begin{array}{l}-0.7654 * * * \\
(0.0523)\end{array}$ & $\begin{array}{l}-0.7985 * * * \\
(0.0579)\end{array}$ \\
\hline Purchase volume (log) & $\begin{array}{l}0.0076^{* *} \\
(0.0038)\end{array}$ & $\begin{array}{l}0.0093 * * \\
(0.0036)\end{array}$ & $\begin{array}{l}0.0093^{* *} \\
(0.0039)\end{array}$ \\
\hline Category size (00s) & $\begin{array}{l}0.0131 \\
(0.0087)\end{array}$ & $\begin{array}{c}0.0126 \\
(0.0086)\end{array}$ & $\begin{array}{c}0.0077 \\
(0.0055)\end{array}$ \\
\hline Model & Logistic & Logistic & OLS \\
\hline Log pseudo-likelihood & $-6,002$ & $-5,990$ & \\
\hline$R^{2}$ or pseudo- $R^{2}$ & 0.1104 & 0.1121 & 0.1272 \\
\hline Sample size & 11,122 & 11,122 & 11,122 \\
\hline
\end{tabular}

The table reports marginal effects from logistic models (models 1 and 2) and coefficients from an OLS model (model 3). In all three models, the dependent variable is a binary variable indicating whether the retailer increased its price following a cost increase. Fixed year and month effects were included but are omitted from this table. Standard errors are in parentheses. The standard errors are clustered by the month of the observation (month $\times$ year). Significantly different from $0, * * p<0.05 ; * * p<0.01$.

Figure 2.-Estimated Probabilities of Price InCrease Following a Cost InCREASE

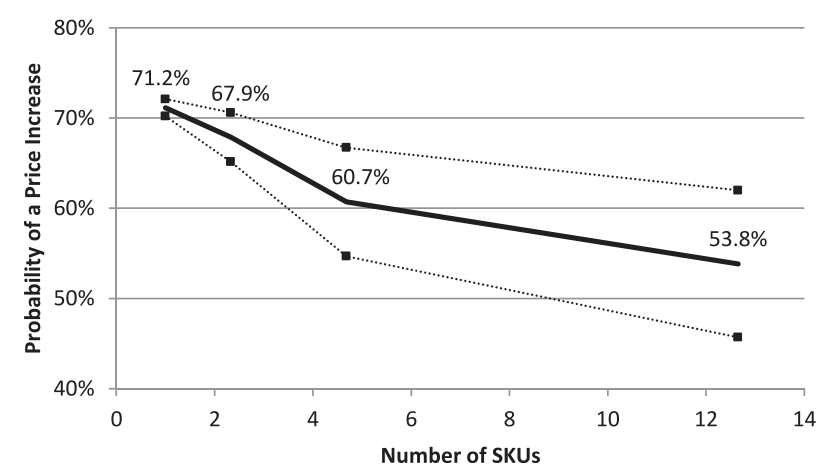

The figure interprets the coefficients from table 5 by reporting the implied probability of a price increase following a cost increase. We index the findings by setting the probability of a price increase for an item with just one variant at $71.2 \%$ (the actual probability). The square markers indicate the $95 \%$ confidence interval. The $x$-axis uses average NUMBER OF SKUS in each of the four product groupings.

First, as expected, the retailer is more likely to increase the price when the cost increase is larger. Second, there is a significant effect of the prior profit margin on the probability of a price change. When the initial profit margin is lower, the firm is more likely to respond to a cost increase with a price increase. Third, if the prior price ended with 99 cents, there is a lower probability of a price change. The size of this effect is striking: the probability of a price increase following a cost increase is approximately $8 \%$ lower when the price has a 99 cent ending. Although this is not the first paper to show that price points affect price stickiness (see Levy et al., 2011; Knotek 2008, 2011), this effect is generally not a central feature of price rigidity analysis and mod- els. The magnitude of the effect that we report suggests that this feature of retail pricing deserves greater attention. Fourth, the firm is more likely to increase prices on items with larger purchase volumes. Finally, we also see evidence that the firm is more likely to increase prices on items that are in larger product categories.

\section{E. Robustness Checks}

In what follows we describe six robustness checks.

Differences in profit margins and quantities sold. If items with more variants have lower profit margins or sell fewer total units, then the benefit of changing prices on these items would be lower. This may explain why the firm is less likely to raise prices on these items. However, there is strong evidence to refute this explanation. First, we explicitly control for the profit margins and unit volumes in our analysis. Second, we compare the median unit volume, revenue, and gross profits at the item level. This comparison reveals that items with multiple variants generally sell more units and have profit margins that are just as high as products with a single variant.

Category fixed effects. Thus far, we have exploited the variation in NUMBER OF SKUS both within and across categories (an example of a category is soda beverages, which includes multiple PrimarySKUs). In practice, much of the variation in NUMBER OF SKUS occurs across categories, and so to investigate the robustness of the results, we reestimated the models with category fixed effects. The 
coefficients of interest again remain statistically significant, though smaller in magnitude than those reported in table 5.

Frequency of cost shocks. Our discussion of the institutional details in section II suggests that the relationship between NUMBER OF SKUS and the probability of a price increase reflects the retailer's focus on minimizing in-store labor costs. Notice that the in-store labor costs associated with changing prices are relevant only for the retailer and do not extend to the manufacturer. Therefore, if our interpretation is correct, we would not expect to see a relationship between NUMBER OF SKUS and the frequency of cost changes. To investigate this, we regressed the number of cost changes in our data period on the same set of explanatory variables that we used in table 5. The findings confirm that there is no evidence that the NUMBER OF SKUS contributed to systematic variation in the frequency of cost changes.

Endogeneity of the number of variants. Another possible concern is that there are other unobserved factors that influence both the probability of a price increase and the number of variants. In an earlier version of the paper, we investigated the possibility that there are other unobserved factors that influence both the probability of a price increase and the number of variants. We explored sources of variation in NUMBER of SKUS and address the potential endogeneity with an instrumental variables (IV) model. As instruments, we used measures of the heterogeneity in preferences across customers. The results survived in the IV model.

Items with a single variant. From table 3, we can see a large mass of observations for which there is only a single variant. To investigate how this affected the estimates, we reestimated the models when omitting these items. For the linear probability model (model 3), we omitted the Number of SKUs $=2$ or 3 variable and use these observations as the baseline (previously we used Number of SKUs $=1$ as the baseline). We report the findings in the online appendix and again observe the same pattern of significant results.

Additional control variables. We also investigated estimating the model with a series of additional control variables, including how often costs change (or increase) annually, whether the item has the retailer's private label brand (or a national brand), and the retail price of the item prior to the cost increase. ${ }^{19} \mathrm{We}$ also investigated replacing

\footnotetext{
${ }^{19}$ The frequency of cost changes provides a measure of volatility, which can increase the option value of delaying a price increase (see Barro, 1972). There is some evidence that private label items are less price sensitive and clear evidence that they have different profit margin targets (see Barksy et al., 2003). The retail price could be relevant if price endings become less of a constraint for items with higher prices, and the inclusion of both price and unit sales volume allows the model to capture any sensitivity to revenue instead of just unit volume. Controlling for unit volume per SKU instead of unit volume per PrimarySKU addresses the possibility that the retailer is sensitive to volume at the SKU level rather than the PrimarySKU level.
}

Figure 3.--Estimated Probabilities of Price Increase Following a Cost INCREASE By Size of COST INCREASE

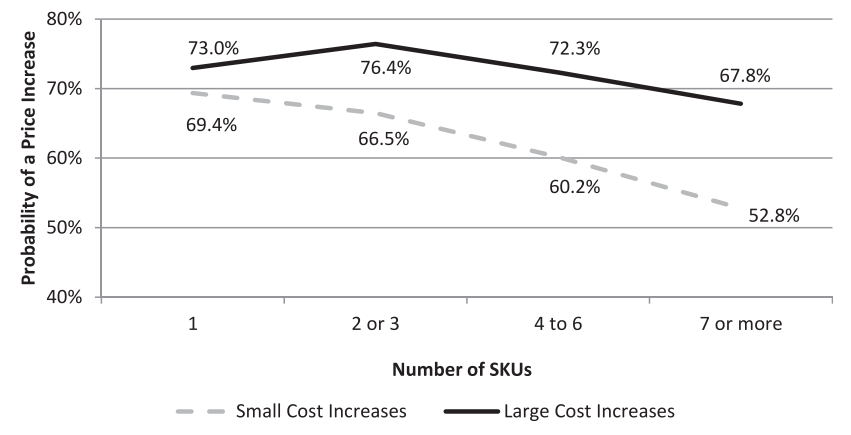

The figure report the probability of a price increase following a cost increase. It uses the same sample of observations as those used in table 5. Small cost increases include the 5,645 observations with cost increases less than the median $(5.98 \%)$, and the large cost increases include the 5,646 observations with cost increases larger than the median.

the unit volume measure with a revenue measure and controlling for unit volume per SKU (rather than unit volume per PrimarySKU). The findings for all of these specifications are reported in the online appendix. Reassuringly, the coefficients of interest remained significant and relatively stable under each of these modifications.

\section{F. Isolating When Menu Costs Play a More Prominent Role}

We would expect that the contribution of menu costs to price stickiness would depend on the firm's other motivations for changing the price. In particular, we know from table 5 that when the cost increase is large enough, the firm is highly motivated to increase the price. In these cases, we might expect a price change irrespective of the menu costs. In contrast, when the cost change is small, the motivation to increase prices is weaker. This is when we would expect menu costs to play a more prominent role.

To investigate this prediction, we used the median-sized cost increase $(5.98 \%)$ to split the sample into two subsamples of equal size. In figure 3, we illustrate how the probability of a price increase varied with the number of variants for each of these subsamples. For large cost increases, we see that the number of variants has relatively little impact on the probability of a price increase. When we move from an item with a single variant to an item with seven or more variants the probability of a price increase only varies from $73.0 \%$ to $67.8 \%$.

However, when the cost increase is small, menu costs appear to play a much larger role. For items with a single variant, the probability of a price change is relatively high (comparable to the probabilities for large cost increases). This is consistent with relatively small menu costs providing little disincentive to changing prices. However, as the number of variants grows, the probability of a price increase (after a small cost increase) falls from $69.4 \%$ to just $52.8 \%$. These findings can be interpreted as some of the first empirical evidence of boundary conditions for the 
menu cost channel. They suggest that the menu cost channel plays a more central role when cost changes are relatively small and the firm has a weaker motivation for changing prices.

In the online appendix, we formally estimate how the interaction between NUMBER OF SKUS and Size of Cost Change affects the probability of a price increase in our multivariate model. The findings replicate the pattern observed in figure 3 . The larger the number of variants, the lower the probability of a price increase, but this effect is attenuated when the cost increase is larger. ${ }^{20}$

\section{G. Summary}

We have shown that the firm is less likely to respond to a cost increase by increasing the price when the item has more variants. While cost increases lead to price increases $71.2 \%$ of the time on items with a single variant, this falls to $59.8 \%$ on items with seven or more variants. We attributed this increased stickiness in the prices of items with more variants to the additional in-store labor costs of changing prices on items with multiple variants. In particular, this behavior is consistent with the firm's internal management policies, which are designed to deter frequent price changes that would exceed the firm's in-store labor capacity. Reassuringly, the findings survive controlling for a range of other factors that contribute to the decision to increase prices following a cost increase.

We have exploited a unique feature of the data that documents each unique cost change event and the firm's explicit pricing decision at that time. For this reason, our analysis has focused on immediate price changes that coincide with the cost change. However, it is possible that the pricing response to a cost change is merely delayed to allow the firm to smooth out price changes and operate within its instore labor capacity constraint. We investigate this possibility in the next section by asking, How sticky is sticky? In particular, if the firm forgoes a price increase when a cost increases, does this accelerate the timing of the next price increase?

\section{How Sticky Is Sticky?}

The analysis in this section proceeds in three steps. First, we focus on the items that had cost increases and report how many of them had a price increase within the next 30 , 90,180 , or 360 days. In doing so, we exclude any initial price increases that occurred at the time of the cost increase (we studied these in section III). Second, we use our sample of store transaction data and report the weekly trends in the prices and profit margins in the weeks after the cost

\footnotetext{
${ }^{20}$ The interaction coefficient is significantly different from $0(p<0.01)$ when using the log transformation of NUMBER OF SKUS (model 2) but not significant $(p<0.10)$ without the log transformation (model 1).
}

Table 6.-Proportion of Items with a Future Price Increase

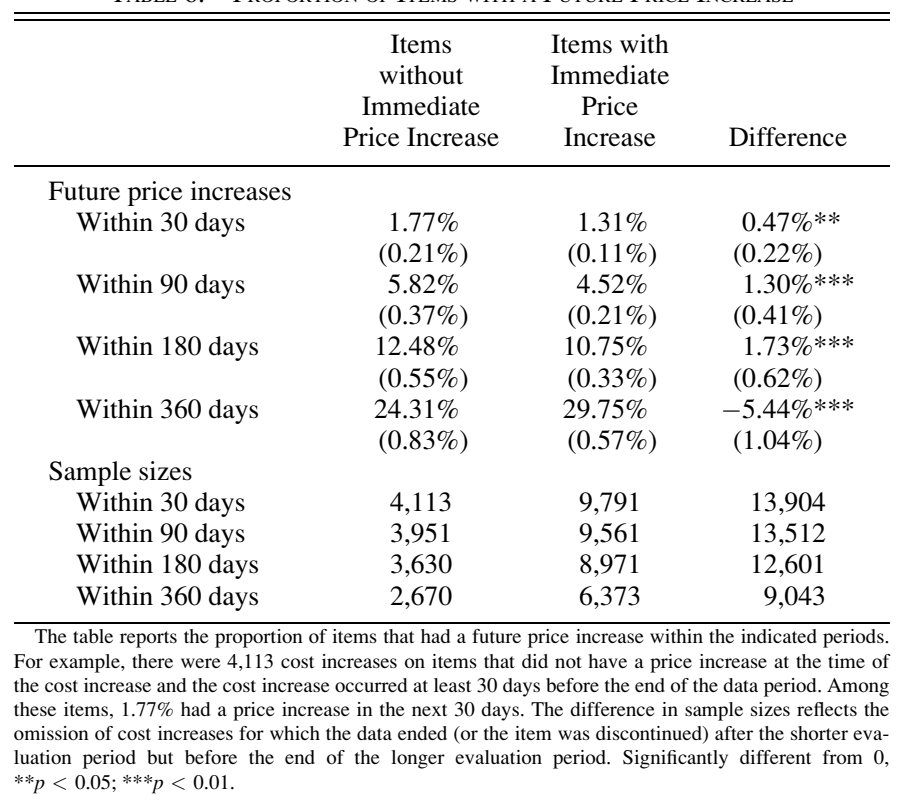

increase. We conclude the section by investigating whether the effects are allocative, in the sense that they had longterm impacts on the quantities purchased.

\section{A. Frequency of Subsequent Price Increases}

To investigate the possibility that not raising the price at the time of a cost increase merely results in a short delay in the timing of the price increase, we compare the incidence of future price increases. In particular, for each observation (cost increase), we report whether there was a price increase in the next 30 days, 90 days, 180 days, and 360 days. For cost increases that had an immediate price increase, we do not count this initial price increase when evaluating whether there was a price increase in the subsequent periods. ${ }^{21}$ The results are reported in table 6 , where we distinguish between items with and without an immediate price increase.

Of the cost increase events without an immediate price increase, 4,113 events occurred at least 30 days before the end of the 55 month data period. Among these, only $1.77 \%$ had a price increase in the 30 days after the cost increase. This is a very small proportion and indicates that for the vast majority of these events, forgoing a price increase at the time of the cost increase is not merely a short delay in the timing of the price increase. After 180 days, we observe a subsequent price increase for only $12.48 \%$ of these events.

The results in table 6 reveal that items that do not have an immediate price increase were slightly more likely to

\footnotetext{
${ }^{21}$ We also exclude any items that were discontinued within the specified evaluation period or cost increases that occurred too close to the end of the data period to observe whether there were subsequent price increases.
} 
have a future price increase in the next 30 days, 90 days, and 180 days. However, the differences in these probabilities between the two groups of items is relatively small and thus not large enough to compensate for the difference in the initial decision whether to increase the price at the time of the cost increase.

Because this retailer requires that manufacturers provide advance notice of impending cost changes, it is possible that the retailer changes the retail price before the cost changes take effect. In particular, it is possible that the retailer increased prices in anticipation of future cost increases. To investigate this possibility, we also evaluated the incidence of prior price increases. This analysis reveals that only $2 \%$ of the items had a prior price increase within 30 days of the cost increase. This proportion is slightly higher for items on which the firm did not raise prices at the time of the cost increase (3.7\% versus $1.4 \%$ ). While this may reflect the firm's raising prices in anticipation of the cost increase (rather than raising prices at the time of the cost increase), this difference is again too small to fully compensate for the different pricing decisions at the time of the cost increase.

We have shown is little evidence that the firm "smooths" the frequency of price changes by delaying price changes to future periods (or accelerating them to prior periods). The incidence of future (and prior) price increases is only slightly higher if the price did not increase when the cost increased. However, simply comparing the incidence of future price changes does not capture any differences in the magnitude of those future price increases. Thus in our next analysis, we compare the prices and profit margins of the two groups of items over the subsequent twelve months. This reveals the net impact of the (small) difference in the frequency of future price changes, together with any differences in the magnitude of those price changes.

\section{B. Do the Prices and Profit Margins Recover?}

Recall that we documented in section III that the firm was more likely to raise prices on items that had lower initial profit margins. We interpreted this as evidence that the firm's pricing decisions were designed to maintain profit margins within a target range. While the initial decision to increase prices on some items and not on others will lead to initial divergence in the profit margins of these items, we would expect that this divergence will eventually be mitigated if the firm's goal is to maintain margins within a target range.

To investigate the trend in the prices and profit margins, we turn to our sample of weekly store transactions. Recall that our transaction data report aggregates weekly storelevel transactions for every item in a sample of 102 stores for the period between January 2006 and October 2009. We use the 52 weeks before the cost change to calculate baseline averages for the Retail Price and Profit Margin
Figure 4.-Difference in Price and Profit Margin IndeXes for Items with and Without a Price Increase at the time of the Cost IncRease

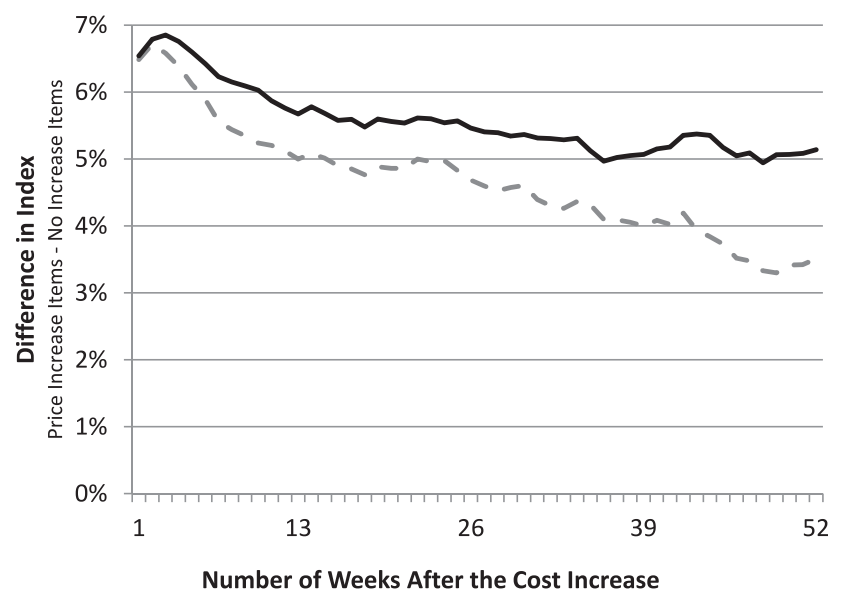

- - Margin Difference $\quad$ Retail Price Difference

The $x$-axis identifies the number of weeks after a cost increase. The $y$-axis describes the difference in the average Profit Margin and Retail Price indexes for items that had a price increase in week 0 (at the time of the cost increase) and items that did not. Positive (negative) values indicate that items with a price increase had a higher (lower) index than items that did not. The indexes represent percentage price increase had a higher (lower) index than items that did not. The indexes represent percentage
changes from the prior 52 -week baseline period. The analysis includes only items that had sales in each of the 52 weeks before and after the cost increase. For items that had multiple qualifying cost increases, we focus on the first cost increase. The sample sizes include 1,701 items that had a price increase at the time of the cost increase and 633 items that did not.

for each item. ${ }^{22}$ In the 52 weeks after the baseline, we calculate the percentage change from the baseline to yield a weekly Retail Price Index and a weekly Profit Margin Index for each item. To compare how the initial pricing decision at the time of the cost increase affected these indexes, we calculate the difference in the weekly indexes between items that had an initial price increase and those that did not. The findings are reported in figure 4.

As we would expect, the initial price increase at the time of the cost increase resulted in higher prices and higher margins for these items. This is reflected in figure 4, where the difference in the indexes indicates that in the weeks immediately after the cost increase, prices and profit margins were almost $7 \%$ higher on items that had an initial price increase (compared to items without an initial price increase). In subsequent weeks, the differences steadily decreased, indicating that the price and margin indexes for the two groups of items began to converge. After 52 weeks, approximately half of the initial difference in the profit margins remained.

The trends in figure 4 confirm that the effects of the initial pricing decision are enduring rather than transitory. Persistent differences in both the indexed retail prices and the profit margins remain even a year later. We next ask whether these differences were allocative.

\footnotetext{
${ }^{22}$ In the transaction data, we observe prices and profit margins only in weeks for which there was a transaction, and so we restrict attention to items for which there were 52 weeks of consecutive transactions after the cost increase and 52 weeks of consecutive transactions before the cost increase. This ensures that the weekly outcomes are calculated using the same sample of items. For items with multiple qualifying cost increases (105 weeks of consecutive sales), we focus on the first cost increase.
} 
Table 7.-Transaction Outcomes in the 52 Weeks after the Cost Increase

\begin{tabular}{cccc}
\hline \hline & $\begin{array}{c}\text { Items } \\
\text { without } \\
\text { Immediate } \\
\text { Price Increase }\end{array}$ & $\begin{array}{c}\text { Items with } \\
\text { Immediate } \\
\text { Price } \\
\text { Increase }\end{array}$ & Difference \\
\hline Quantity sold & $1.91 \%$ & $-3.21 \%$ & $-5.12 \% * * *$ \\
& $(0.70 \%)$ & $(0.42 \%)$ & $(0.77 \%)$ \\
Retail price & $6.53 \%$ & $12.49 \%$ & $5.96 \% * * *$ \\
& $(0.25 \%)$ & $(0.15 \%)$ & $(0.27 \%)$ \\
Cost & $7.21 \%$ & $9.41 \%$ & $2.19 \% * * *$ \\
Sample size & $(0.31 \%)$ & $(0.14 \%)$ & $(0.29 \%)$ \\
& 1,033 & 2,674 & \\
\hline
\end{tabular}

The table reports the percentage change in each measure in the 52 weeks after the cost increase compared to the previous 52 weeks. The measures for each item are weighted using the quantity sold in the baseline period. The table distinguishes between observations in which the cost increase resulted in an immediate price increase and those that did not. Standard errors are in parentheses. Significantly different from $0, * * p<0.05 ; * * * p<0.01$.

\section{Is the Decision to Increase Prices Allocative?}

To evaluate the importance of the effects that we report, it is helpful to understand the extent to which they influenced the number of items that were purchased in subsequent periods. We address this issue by comparing sales in the 52 weeks after the cost increase between our two groups of items. In table 7 we report these averages as the percentage difference compared to the 52-week baseline period. ${ }^{23}$ As a basis of comparison, we also report the average retail price and cost in the year after the cost increase. When averaging across items, the items are weighted using the quantity sold in the baseline period.

The findings confirm that the decision to increase the price in response to a cost increase is allocative; there is a significant impact on the quantity sold over the next 52 weeks. Without a price increase, there was a $1.91 \%$ increase in quantity sold compared to the baseline period. In contrast, items with an initial price increase had a $3.21 \%$ decrease in units sold over the same period. The difference between these two outcomes reveals a net loss of $5.12 \%$ in unit sales growth for items that had a price increase at the time of the cost increase. This $5.12 \%$ lower sales growth can be compared to the $5.96 \%$ larger increase in retail prices over the same period. This corresponds to an average price elasticity of approximately -1 .

\section{Summary}

We have presented evidence that the decision to forgo a price increase when the cost increases is not just a decision to delay the price increase. Moreover, a comparison of indexed prices and profit margins in the period after the initial price increase confirms that the effects of the initial pricing decision are persistent. The retail prices and profit

\footnotetext{
${ }^{23}$ To control for changes in product lines at different stores, we restrict attention to stores in which the item was introduced prior to the 52-week baseline period and was continued through the 52-week evaluation period. This yields a larger sample size than the analysis in table 5, where we required sales in every week of the baseline and evaluation periods.
}

margins converge slowly over the next 52 weeks, with enduring differences even at the end of the period.

We also investigated whether the outcome is allocative by evaluating how the decision to increase prices at the time of the cost increase influences the prices and quantities sold over the next 52 weeks. The findings confirm that the initial pricing decision is not just sticky; it also affects transaction outcomes. Items that had an initial price increase experienced a net $5.12 \%$ drop in units sold (relative to items without an initial price increase).

To this point, we have focused on cost increases. In the next section we investigate the firm's response to cost decreases.

\section{The Response to Cost Decreases}

While we might expect a similar pattern of findings if we study the response to cost increases and cost decreases, the literature suggests otherwise. A growing body of evidence suggess that firms use different criteria for deciding when to increase versus decrease the price and that this leads to asymmetries. $^{24}$ In this section we search for further evidence of asymmetries by measuring how often the retailer decreases prices in response to a cost decrease.

The price and cost change database has 4,194 examples of cost decreases over a four-year period. In section III, we reported that just $9.2 \%$ of these cost decreases resulted in price decreases $(5.7 \%$ led to price increases). In comparison, recall that cost increases resulted in price increases $70.6 \%$ of the time. While cost increases often lead to a price increase, cost decreases rarely result in price decreases. Discussions with the managers at the retailer confirmed that the decision to lower a price depends on factors different from those to increase prices. In particular, price decreases are often made in response to competitive price comparisons. When a price is high relative to geographically close competitors, the price may be adjusted downward. Without evidence that competing retailers have lowered their prices, there is a strong incentive to maintain the status quo price.

To investigate factors that affected the probability of a price decrease, we reestimated our logistic and OLS models using a new dependent measure. The new (binary) dependent variable indicates whether the price decreased following a cost decrease. The findings are reported in table 8.

The results reveal no evidence that the decision to decrease the price is related to NUMBER OF SKUS. This is somewhat surprising, as the argument that it is more costly to change prices on items with multiple variants applies equally to price increases and decreases. The results also contrast sharply with the evidence that the number of variants influences the retailer's willingness to increase prices.

\footnotetext{
${ }^{24}$ As we acknowledged in section III, asymmetries between price increases and price decreases have been recognized elsewhere in the literature.
} 
Table 8.-Factors Contributing to the Decision to Lower the Price

\begin{tabular}{|c|c|c|c|}
\hline & Model 1 & Model 2 & Model 3 OLS \\
\hline NUMBER OF SKUS & $\begin{array}{r}-0.0009 \\
(0.0024)\end{array}$ & & \\
\hline Log NUMBER OF SKUS & & $\begin{array}{c}0.0083 \\
(0.0104)\end{array}$ & \\
\hline NUMBER OF SKUS $=2$ or 3 & & & $\begin{array}{c}0.0255 \\
(0.0192)\end{array}$ \\
\hline NUMBER OF SKUS $=4$ to 6 & & & $\begin{array}{c}0.0186 \\
(0.0315)\end{array}$ \\
\hline NUMBER OF SKUS $=7$ or more & & & $\begin{array}{r}-0.0245 \\
(0.0271)\end{array}$ \\
\hline Prior 99-cent price ending & $\begin{array}{c}-0.0065 \\
(0.0112)\end{array}$ & $\begin{array}{c}-0.0058 \\
(0.0112)\end{array}$ & $\begin{array}{c}-0.0079 \\
(0.0108)\end{array}$ \\
\hline Absolute size of cost decrease (\%) & $\begin{array}{l}0.3922 * * * \\
(0.0443)\end{array}$ & $\begin{array}{l}0.3946^{* * * *} \\
(0.0444)\end{array}$ & $\begin{array}{l}0.5589 * * * \\
(0.0747)\end{array}$ \\
\hline Prior profit margin (\%) & $\begin{array}{l}-0.2196 * * * \\
(0.0440)\end{array}$ & $\begin{array}{l}-0.2151 * * * \\
(0.0437)\end{array}$ & $\begin{array}{l}-0.1873 * * * \\
(0.0393)\end{array}$ \\
\hline Purchase volume (log) & $\begin{array}{l}-0.0082 * * * \\
0.0030)\end{array}$ & $\begin{array}{l}-0.0085^{* * *} \\
(0.0031)\end{array}$ & $\begin{array}{l}-0.0095 * * \\
(0.0045)\end{array}$ \\
\hline Category size (00s) & $\begin{array}{c}-0.00001 \\
(0.0051)\end{array}$ & $\begin{array}{c}0.0002 \\
(0.0051)\end{array}$ & $\begin{array}{c}0.0051 \\
(0.0119)\end{array}$ \\
\hline Model & Logistic & Logistic & OLS \\
\hline Log pseudo-likelihood & $-1,044$ & $-1,044$ & \\
\hline$R^{2}$ or pseudo- $R^{2}$ & 0.1642 & 0.1645 & 0.1084 \\
\hline Sample sizes & 4,120 & 4,120 & 4,120 \\
\hline
\end{tabular}

The table reports marginal effects from logistic models (models 1 and 2) and coefficients from an OLS model (model 3). In all three models, the dependent variable is a binary variable indicating whether the retailer decreased the price following a cost decrease. Fixed year and month effects were included but are omitted from this table. Standard errors are in parentheses. The standard errors are clustered by the month of the observation (Month $\times$ Year). Significantly different from $0, * * p<0.05 ; * * *<0.01$

They represent further evidence of asymmetries in the way that retailers evaluate price increases and price decreases. ${ }^{25}$

\section{Conclusion}

Starting with the seminal work of Barro (1972) and Sheshinksi and Weiss (1977), much of the analysis of monetary policy effects has relied on models with fixed costs of price adjustment. Yet there has been little microevidence validating and quantifying the effects these costs have on the probability of price adjustments.

Building on a 55-month database of cost and price changes at a large retailer, this paper helps to fill this gap. We find that variation in menu costs leads to up to $13.3 \%$ fewer price increases. The identification of this effect stems from the retailer's pricing rule that requires all variants of a product to have the same price. Since different products have a different number of variants, this pricing rule leads to variation in the opportunity cost of changing prices across products.

In addition to documenting existence of the menu cost channel, we also identify boundary conditions. First, we find no evidence of a menu cost channel for cost decreases and price decreases. Second, when cost increases are very large, we find that the decision to raise price is independent of menu costs. But for smaller cost increases, we find that the menu cost channel plays a central role.

\footnotetext{
${ }^{25}$ To further investigate the response to cost decreases, we also replicated the analysis in figure 4 for cost decreases, revealing the paths of the prices and markups over the next 52 weeks (this figure is reported in the online appendix). Because we track cost decrease events for the next year and many of the decreases occur near the end of the data, the sample includes only 27 cost decrease events in which the firm responded with a price decrease.
}

A limitation of our research is that we study a single retail chain. However, this allows us to understand important institutional facts and acquire unique data. Both are essential to understanding the menu cost channel. Further, while we study a single retailer, we analyze a census of products offered by the retailer. In this sense, our empirical study is extremely large as we analyze thousands of brands and hundreds of manufacturers. Future work is needed to investigate the menu cost channel in other empirical settings.

\section{REFERENCES}

Akerlof, George A., and Janet L. Yellen, "Can Small Deviations from Rationality Make Significant Differences to Economic Equilibria?" American Economic Review 75 (1985a), 708-720.

Akerlof, George A., and Janet L. Yellen, "A Near-Rational Model of the Business Cycle, with Wage and Price Inertia," Quarterly Journal of Economics 100 (1985b), 823-838.

Alvarez, Fernando, and Francesco Lippi, "Price Setting with Menu Costs for Multi-Product Firms," Econometrica 82 (2014) 89-135.

Anderson, Eric T., and James Dana, "When is Price Discrimination Profitable?" Management Science 55 (2009), 980-989.

Anderson, Eric T., Emi Nakamura, Duncan I. Simester, and Jón Steinsson, "Informational Rigidities and the Stickiness of Temporary Sales," working paper (2015).

Anderson, Eric T., and Duncan I. Simester, "Does Demand Fall When Customers Perceive That Prices Are Unfair? The Case of Premium Pricing for Large Sizes," Marketing Science (2001), 492-500.

"Price Discrimination as a Signal: Why an Offer to Spread Payments May Hurt Demand," Marketing Science 20 (2008), 315327.

Atlanta Retail Consulting, The Retail Store Labor Management Improvement Process (2011), http://www.atlantaretailconsulting.com /documents/ARC_Labor_Management_Whitepaper.pdf.

Ball, Laurence, and N. Gregory Mankiw, "Asymmetric Price Adjustment and Economic Fluctuations," working paper 4089 (1992).

Ball, Laurence N., Gregory Mankiw, David Romer, George A. Akerlof, Andrew Rose, Janet Yellen, and Christopher A. Sims, "The New 
Keynesian Economics and the Output-Inflation Trade-Off," Brookings Papers on Economic Activity 1988:1 (1988), 1-82.

Barro, Robert J., "A Theory of Monopolistic Price Adjustment," Review of Economic Studies 39 (1972), 17-26.

Barsky, Robert B., Mark Bergen, Shantanu Dutta, and Daniel Levy, "What Can the Price Gap between Branded and Private-Label Products Tell Us about Markups?" in Robert C. Feenstra and Matthew D. Shapiro, eds., Scanner Data and Price Indexes (Chicago: University of Chicago Press, 2003).

Bertola, Giuseppe, and Ricardo Caballero, "Kinked Adjustment Costs and Aggregate Dynamics," in O. J. Blanchard and S. Fischer, eds., NBER Macroeconomics Annual (Cambridge, MA: MIT Press, 1990).

Bhattarai, Saroj, and Raphael Schoenle, "Multiproduct Firms and PriceSetting: Theory and Evidence from the U.S. Producer Prices," Journal of Monetory Economics 66 (2014), 178-192.

Bils, Mark, and Peter J. Klenow, "Some Evidence on the Importance of Sticky Prices," Journal of Political Economy 112 (2004) , 947985.

Borenstein, Severin, A. Colin Cameron, and Richard Gilbert, "Do Gasoline Prices Respond Asymmetrically to Crude Oil Price Changes?" Quarterly Journal of Economics 112 (1997), 305-339.

Burstein, Ariel, "Inflation and Output Dynamics with State Dependent Pricing Decisions," Journal of Monetary Economics 53 (2006), 1235-1257.

Caplin, Andrew, and Daniel Spulber, "Menu Costs and the Neutrality of Money," Quarterly Journal of Economics 102 (1987), 703-725.

Caplin, Andrew, and John Leahy, "State-Dependent Pricing and the Dynamics of Money and Output," Quarterly Journal of Economics 106 (1991), 683-708.

"Aggregation and Optimization with State-Dependent Pricing," Econometrica 65 (1997), 601-625.

Carlton, Dennis W., "The Rigidity of Prices," NBER working paper 1813 (1986).

Cecchetti, Steven, "The Frequency of Price Adjustment: A Study of the Newsstand Prices of Magazines," Journal of Econometrics 31 (1986), 255-274.

Danziger, Leif, "Inflation, Fixed Cost of Price Adjustment, and Measurement of Relative-Price Variability: Theory and Evidence," American Economic Review 77 (1987), 704-713.

"A Dynamic Economy with Costly Price Adjustments," American Economic Review 89 (1999), 878-901.

Dotsey, Michael, Robert G. King, and Alexander L. Wolman, "StateDependent Pricing and the General Equilibrium Dynamics of Money and Output," Quarterly Journal of Economics 114 (1999), 655-690.

Draganska, Michaela, and Dipak C. Jain, "Product-Line Length Decisions in a Competitive Environment," Graduate School of Business, Stanford University working paper (2001).

"Consumer Preferences and Product-Line Pricing Strategies" Marketing Science 25 (2006), 164-174.

Dutta, Shantanu, Mark Bergen, Daniel Levy, and Robert Venable, "Menu Costs, Posted Prices, and Multiproduct Retailers," Journal of Money, Credit and Banking 31 (1999), 683-703.

FMI Research, The Food Retailing Industry Speaks (Arlington, VA: Food Marketing Institute, 2008)

Gertler, Mark, and John Leahy, "A Phillips Curve with an Ss Foundation," Journal of Political Economy 116 (2008), 533-572.

Golosov Mikail, and Robert E. Lucas Jr., "Menu Costs and Phillips Curves," Journal of Political Economy 115 (2007), 171-199.

Green, Richard C., Dan Li, and Norman Schuerhoff, "Price Discovery in Illiquid Markets: Do Financial Asset Prices Rise Faster Than They Fall?" Journal of Finance 65 (2010), 1669-1702.

Hauser, John R., and Birger Wernerfelt, "An Evaluation Cost Model of Consideration Sets," Journal of Consumer Research 16 (1990), 393-408.

Hofstetter, Marc, and Jorge Tover, "Common Knowledge Reference Price and Asymmetric Price Adjustments," Review of Industrial Organization 37 (2010), 141-159.

Iyengar, Sheena S., and Mark R. Lepper, "When Choice Is Demotivating: Can One Desire Too Much of a Good Thing?" Journal of Personality and Social Psychology 79 (2000), 995-1006.

Jackson, William E. III, "Market Structure and the Speed of Price Adjustments: Evidence of Non-Monotonicity," Review of Industrial Organization 12 (1997), 37-57.
Karrenbrock, Jeffrey D., "The Behavior of Retail Gasoline Prices: Symmetric or Not?" Federal Reserve Bank St. Louis Review 73 (1991), 19-29.

Kashyap, Anil K., "Sticky Prices: New Evidence from Retail Catalogs," Quarterly Journal of Economics, 110 (1995), 245-274.

Klenow, P. J., and O. Kryvtsov, "State-Dependent or Time-Dependent Pricing: Does It Matter for Recent U.S. Inflation?" Quarterly Journal of Economics, 123 (2008), 863-904.

Knotek, Edward S. II, "Convenient Prices, Currency and Nominal Rigidity: Theory with Evidence from Newspaper Prices." Journal of Monetary Economics 55 (2008), 1303-1316.

"Convenient Prices and Price Rigidity: Cross-Sectional Evidence," this REVIEW 93 (2011), 1076-1086.

Lach, Saul, and Daniel Tsiddon, "The Behavior of Prices and Inflation: An Empirical Analysis of Disaggregate Price Data," Journal of Political Economy (1992), 349-389.

"Staggering and Synchronization in Price Setting: An Empirical Analysis of Disaggregated Data," American Economic Review 86 (1996), 1175-1196.

"Small Price Changes and Menu Costs," Managerial and Decision Economics 28 (2007), 649-656.

Leslie, Phillip, "Price Discrimination in Broadway Theater," RAND Journal of Economics 35 (2004), 520-541.

Levy, Daniel, Mark Bergen, Shantanu Dutta, and Robert Venable, "The Magnitude of Menu Costs: Direct Evidence from Large U. S. Supermarket Chains," Quarterly Journal of Economics 112 (1997), 791-825.

Mark Bergen, and Robert Venable, "Price Adjustment at Multiproduct Retailers," Managerial and Decision Economics 19 (1998), 81-120.

Levy, Daniel, Dongwon Lee, Haipeng (Allan) Chen, Robert J. Kauffman, and Mark Bergen, "Price Points and Price Rigidity," this REVIEW 93 (2011), 1417-1431.

Mankiw, N. Gregory, "Small Menu Costs and Large Business Cycles: A Macroeconomic Model," Quarterly Journal of Economics 100 (1985), 529-538.

McMillan, Robert S., "Estimating Demand for Differentiated Products with Continuous Choice and Variety-Seeking: An Application to the Puzzle of Uniform Pricing," Ph.D. dissertation, Graduate School of Business, Stanford University (2005).

Midrigan, Virgiliu, "International Price Dispersion in State-Dependent Pricing Models," Journal of Monetary Economics 54 (2007), 2231-2250.

"Menu-Costs, Multi-Product Firms and Aggregate Fluctuations," Econometrica 79 (2011), 1139-1180.

Nakamura, E., and J. Steinsson, "Five Facts about Prices: A Reevaluation of Menu Cost Models," Quarterly Journal of Economics 123 (2008), 1415-1464.

Neumark, David, and Steven A. Sharpe, "Market Structure and the Nature of Price Rigidity: Evidence from the Market for Consumer Deposits," Quarterly Journal of Economics (1992), 657-680.

Noel, Michael, "Do Retail Gasoline Prices Respond Asymmetrically to Cost Shocks? The Influence of Edgeworth Cycles," RAND Journal of Economics 40 (2009), 582-595.

O'Connell, Vanessa, "Stores Count Seconds to Trim Labor Costs," Wall Street Journal, November 13, (2008) http://online.wsj.com/article /SB122651745876821483.html.

Orbach, Barak Y., and Liran Einav, "Uniform Prices for Differentiated Goods: The Case of the Movie-Theater Industry," International Review of Law and Economics 27 (2007), 129-153.

Owen, Ann, and David Trzepacz, "Menu Costs, Firm Strategy and Price Rigidity," Economic Letters 76 (2002) 345-349.

Peltzman, Sam, "Prices Rise Faster Than They Fall," Journal of Political Economy 108 (2000), 466-502.

Rotemberg, Julio, "Monopolistic Price Adjustment and Aggregate Output," Review of Economic Studies 49 (1982), 517-531.

Sheshinski, Eytan, and Yoram Weiss, "Inflation and Costs of Price Adjustment," Review of Economic Studies 44 (1977), 287-303.

Warner, Elizabeth J., and Robert B. Barsky, "The Timing and Magnitude of Retail Store Markdowns: Evidence from Weekends and Holidays," Quarterly Journal of Economics (1995), 321-352.

Zbaracki, Mark, Mark Ritson, Daniel Levy, Shantanu Dutta, and Mark Bergen, "Managerial and Customer Costs of Price Adjustment: Direct Evidence from Industrial Markets," this REvIEw 86 (2004), 514-533. 